\title{
Transbronchial needle aspiration in peripheral pulmonary lesions: a systematic review and meta-analysis
}

\author{
Michele Mondoni ${ }^{1}$, Giovanni Sotgiu ${ }^{2}$, Martina Bonifazi ${ }^{3,4}$, Simone Dore², \\ Elena Maria Parazzini ${ }^{1}$, Paolo Carlucci ${ }^{1}$, Stefano Gasparini ${ }^{3,4}$ and Stefano Centanni ${ }^{1}$
}

Affiliations: ${ }^{1}$ Respiratory Unit, San Paolo Hospital, Dept of Scienze della Salute, Università degli Studi di Milano, Milan, Italy. ${ }^{2}$ Clinical Epidemiology and Medical Statistics Unit, Dept of Biomedical Sciences, University of Sassari-Research, Medical Education and Professional Development Unit, AOU Sassari, Sassari, Italy. ${ }^{3}$ Dept of Biomedical Sciences and Public Health, Università Politecnica delle Marche, Ancona, Italy. ${ }^{4}$ Pulmonology Unit, AOU “Ospedali Riuniti”, Ancona, Italy.

Correspondence: Michele Mondoni, Respiratory Unit, San Paolo Hospital, Dept of Scienze della Salute, Università degli Studi di Milano, Via A. Di Rudinì 8, 20142 Milan, Italy.

E-mail: michele.mondonidao-sanpaolo.it

ABSTRACT Fluoroscopy-guided transbronchial needle aspiration (TBNA) has long been used in the diagnosis of peripheral pulmonary lesions (PPLs), although its diagnostic performance varies considerably.

We conducted a systematic review and meta-analysis evaluating the accuracy of TBNA in the diagnosis of PPLs, comparing its diagnostic yield with transbronchial biopsy (TBB) and assessing the main predictors of a successful aspirate.

In 18 studies, the overall TBNA yield was 0.53 (95\% CI 0.44-0.61). TBNA showed a higher accuracy when directly compared to TBB (0.60 (95\% CI $0.49-0.71)$ versus 0.45 (95\% CI $0.37-0.54)$ ). The subgroup analyses documented a higher TBNA yield when the computed tomography (CT) bronchus sign was present (0.70 (95\% CI 0.63-0.77) versus 0.51 (95\% CI 0.38-0.64)), when rapid on-site evaluation (ROSE) was performed $(0.62$ (95\% CI $0.43-0.79)$ versus 0.51 (95\% CI $0.42-0.60)$ ), in the case of malignant lesions (0.55 (95\% CI $0.44-0.66)$ versus 0.17 (95\% CI $0.11-0.24)$ ) and for lesions $>3 \mathrm{~cm}$ (0.81 (95\% CI $0.73-0.87)$ versus 0.55 (95\% CI 0.47-0.63)).

Conventional TBNA is a useful sampling technique for the diagnosis of PPL, with a higher diagnostic yield than TBB. The presence of CT bronchus sign, an underlying malignant process, lesion size $>3 \mathrm{~cm}$ and ROSE employment are predictors of a higher yield.

@ERSpublications

Fluoroscopy-guided transbronchial needle aspiration is a useful technique in diagnosing peripheral pulmonary lesions http://ow.ly/4mK0sB

This article has supplementary material available from erj.ersjournals.com

Received: Jan 082016 | Accepted after revision: April 072016 | First published online: May 122016

Conflict of interest: None declared.

Copyright OERS 2016 


\section{Introduction}

Peripheral pulmonary lesions (PPLs) are defined as focal radiographic opacities not detectable beyond the visual segmental bronchi by flexible bronchoscopy $[1,2]$. In recent years, due to the widespread diffusion of imaging techniques, the detection of PPLs has become even more frequent. The goal, in this context, is to quickly identify malignant nodules in order to allow a curative surgical resection, while avoiding unnecessary invasive interventions in case of benign lesions. In fact, up to $60 \%$ of removed nodules are not malignant, underlining the importance of a diagnostic test that better enables lung preservation [3]. Mini-invasive approaches to establish a tissue diagnosis include imaging-guided transthoracic and bronchoscopic sampling techniques. Although transthoracic needle aspiration, also named percutaneous needle aspiration, is characterised by a higher sensitivity than transbronchial needle aspiration (TBNA), bronchoscopy is widely considered as the first diagnostic step, due to the better safety profile and the advantages of obtaining information on mediastinal staging and airway involvement, and ruling out the possibility of synchronous lesions, during a single examination $[4,5]$.

Despite the recent introduction of innovative and more powerful imaging-guided techniques, such as endobronchial ultrasounds (EBUSs) and electromagnetic navigation, the lack of resources and specific skills in most centres worldwide have strongly limited their diffusion in clinical practice. As a result, traditional fluoroscopy-guided TBNA still plays a relevant role in this context [6].

A limited number of studies have specifically assessed the diagnostic yield of conventional TBNA in diagnosing PPLs, showing a great heterogeneity in terms of sensitivity [5-14]. This could be related to differences in study design, as well as to a number of selected other factors, including both baseline clinical characteristics and procedural aspects. However, the results on such predictors have been often conflicting and the real value of each one has yet to be definitely assessed. Therefore, the aim of the present systematic review was to summarise the available literature in order to provide a pooled estimate of TBNA diagnostic yield and to identify the main predictive factors of a positive transbronchial aspirate according to different clinical conditions.

\section{Material and methods}

This systematic review was conducted according to the guidelines of the PRISMA (Preferred Reporting Items for Systematic Reviews and Meta-Analyses) statement [15] and the inter-rater agreement was analysed for quality assessment of the articles included in the review.

\section{Search strategy}

We selected studies that evaluated the TBNA yield for the diagnosis of PPLs. We searched PubMed and EMBASE until December 2014. The following key words and their related MeSH (Medical Subjects Heading) terms were searched in the databases: "transbronchial needle aspiration", "conventional transbronchial needle aspiration", "transbronchial fine needle aspiration", "transbronchial needle biopsy" and "transbronchial needle aspiration biopsy". Only publications in the English language were considered.

\section{Study selection and data extraction}

Observational/interventional studies of accuracy and/or its predictors of fluoroscopy-guided conventional TBNA in the diagnosis of PPLs were included. The following exclusion criteria were employed. 1) Manuscripts describing observational/interventional studies evaluating TBNA for the diagnosis of PPLs with the guidance of radial probe EBUS, electromagnetic navigation, virtual bronchoscopy and computed tomography (CT) fluoroscopy. 2) Manuscripts describing observational studies also evaluating the yield of TBNA for mediastinal lymphadenopathies/endobronchial lesions where the outcome of interest was not available separately for PPLs, mediastinal nodes and endobronchial lesions. 3) Manuscripts describing studies with sample size <20. 4) Abstracts, editorials, letters, review articles and case reports. 5) Manuscripts published not in English language.

Two independent authors (M. Mondoni and E.M. Parazzini) firstly reviewed all titles/abstracts to identify potentially relevant articles. Then, study selection, based on a full-text review, was performed according to the aformentioned predefined inclusion/exclusion criteria and disagreements were resolved by discussion.

The following data were extracted: authors, title, year of publication, country, enrolment period, sample size, study design, diagnostic yield, study population, lesion size and complications.

\section{Study quality assessment}

The inter-rater agreement was $100 \%$. Quality assessment of individual studies was deemed necessary to identify potential sources of bias and to limit the bias effects on the estimates and the conclusions of the review. We assessed the study for methodological quality using the revised Quality Assessment of Diagnostic Accuracy Studies (QUADAS-2) tool [16]. It consists of four key domains that discuss patient 
selection, index test, flow of patients selection, timing of the index tests and reference standard. Through specified questions, each domain is assessed about risk of bias and the first three items also in terms of concerns about applicability.

\section{Statistical analysis}

Forest plots were constructed to assess graphically both the variability of the estimates of the diagnostic parameters and the weight of every sample size in the calculation of the pooled estimates (weighted means). A random-effects meta-analysis was performed in order to account for the expected between-study variability. The statistical software used was Stata13.0 (StataCorp, College Station, TX, USA) and StatsDirect 2.8.0, version 1.4 (StatsDirect Ltd, Altrincham, UK). Inconsistency (statistical heterogeneity) among studies was assessed by the conventional Chi-squared test for heterogeneity and by calculating the $\mathrm{I}^{2}$ statistic in order to highlight the effect of true variability rather than sampling error on the overall variation in the diagnostic yield.

\section{Results}

Out of 2089 articles selected from the electronic databases, 18 studies were eligible for a qualitative and quantitative analysis (figure 1). The pooled sample size included 1687 patients enrolled from 10 countries (USA [7-9, 17, 18], Japan [14, 19, 20], Italy [4, 5], Spain [6, 10], Poland [21], Greece [11], Turkey [22], India [12], Norway [23], and Switzerland [13]). Mean \pm SD age of the population target was $60.4 \pm 5.8$ years, although data were reported only in eight studies [5-7, 11-14, 22].

The majority of the studies were prospective cohort studies $(11(61 \%)$ out of 18$)[4-9,11,12,17,18,22]$, whereas seven $(39 \%)$ out of $18[10,13,14,19,20,21,23]$ were retrospective investigations. Some studies (nine $(50.0 \%)$ out of 18$)[7,9,10,14,19,20-23]$ enrolled patients with suspected or known pulmonary malignancy; the remaining selected studies included subjects with undefined nodules. The diagnostic yield

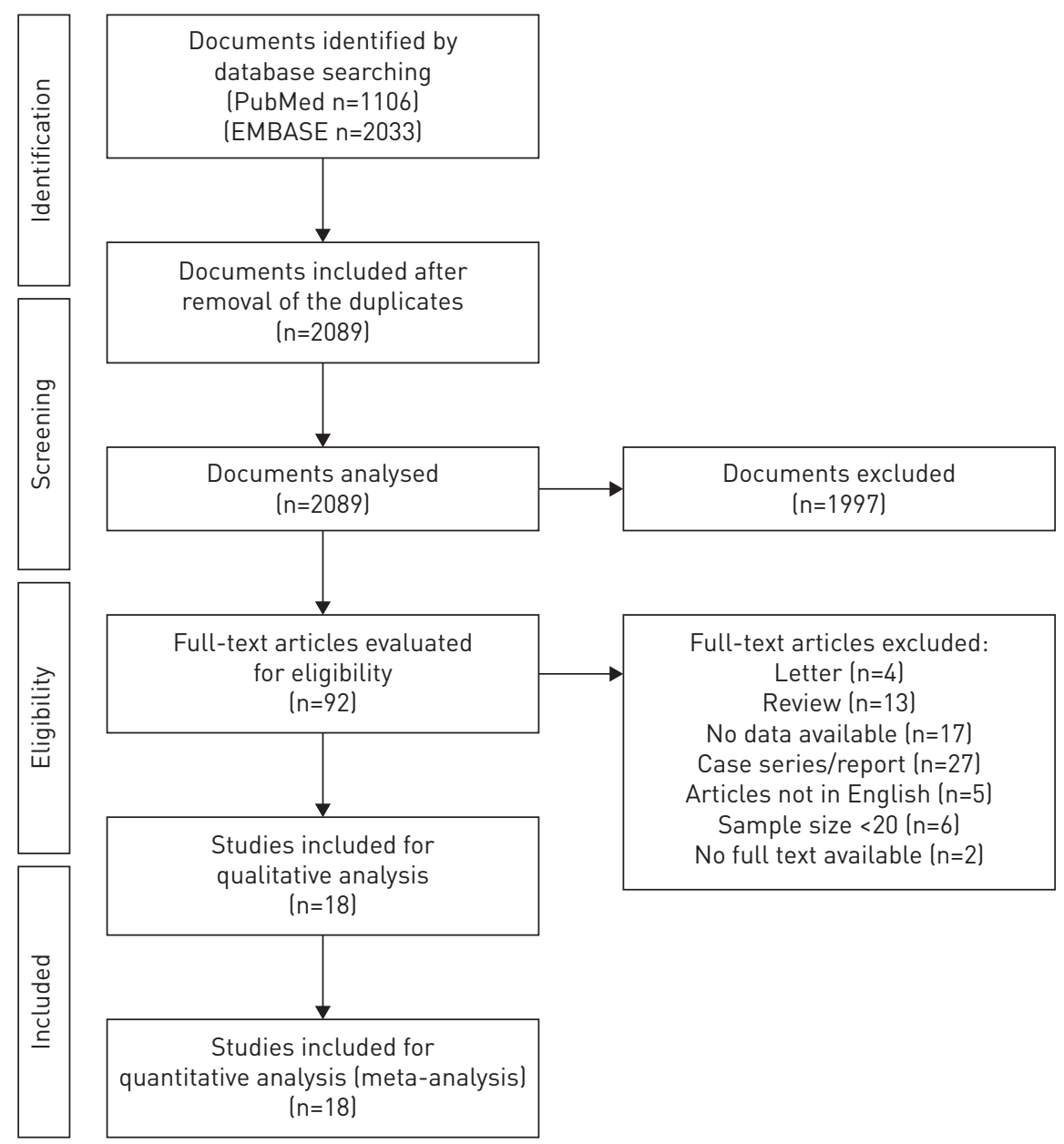

FIGURE 1 PRISMA (Preferred Reporting Items for Systematic Reviews and Meta-Analyses) 2009 flow diagram. 


\begin{tabular}{|c|c|c|c|c|c|c|c|c|c|c|c|c|}
\hline \multirow[t]{2}{*}{ First author [ref.] } & \multirow[t]{2}{*}{ Country } & \multirow{2}{*}{$\begin{array}{l}\text { Study } \\
\text { design }\end{array}$} & \multirow[t]{2}{*}{ Patients } & \multirow{2}{*}{$\begin{array}{l}\text { Age } \\
\text { years }\end{array}$} & \multirow{2}{*}{$\begin{array}{l}\text { Yield } \\
\text { results }\end{array}$} & \multirow[t]{2}{*}{ Population } & \multicolumn{4}{|c|}{ Yield according to } & \multirow{2}{*}{$\begin{array}{l}\text { TBNA versus TBB } \\
\text { comparison }\end{array}$} & \multirow[t]{2}{*}{ Complications } \\
\hline & & & & & & & $\begin{array}{l}\text { Lesion } \\
\text { size }\end{array}$ & ROSE & $\begin{array}{l}\text { CT bronchus } \\
\text { sign }\end{array}$ & Disease type & & \\
\hline BABA [19] & Japan & RCS & 78 & & $66.6 \%$ & $\begin{array}{l}\text { Suspected/known } \\
\text { malignancy }\end{array}$ & & $\begin{array}{l}\text { Reported } \\
\text { (present) }\end{array}$ & & $\begin{array}{l}\text { Reported } \\
\text { (malignant) }\end{array}$ & & \\
\hline BILAC̣EROGLU [22] & Turkey & PCS & 92 & $\begin{array}{c}51 \\
\text { (mean) }\end{array}$ & $52.0 \%$ & $\begin{array}{l}\text { Suspected/known } \\
\text { malignancy }\end{array}$ & & $\begin{array}{l}\text { Reported } \\
\text { (absent) }\end{array}$ & Reported & & Performed & $\begin{array}{c}1 \text { PNT } \\
1 \text { moderate } \\
\text { bleeding }\end{array}$ \\
\hline Castella [10] & Spain & RCS & 45 & & $69.0 \%$ & $\begin{array}{l}\text { Suspected/known } \\
\text { malignancy }\end{array}$ & Reported & $\begin{array}{l}\text { Reported } \\
\text { (absent) }\end{array}$ & & & & None \\
\hline Checkani [17] & USA & PCS & 37 & & $51.0 \%$ & Unselected & & $\begin{array}{l}\text { Reported } \\
\text { (absent) }\end{array}$ & & & & $\begin{array}{l}3 \text { moderate } \\
\text { bleeding }\end{array}$ \\
\hline GASPARINI [4] & Italy & PCS & 435 & & $59.1 \%$ & Unselected & & $\begin{array}{l}\text { Reported } \\
\text { (present) }\end{array}$ & & $\begin{array}{l}\text { Reported } \\
\text { (malignant/ } \\
\text { benign) }\end{array}$ & Performed & 1 PNT \\
\hline GUPTA [12] & India & PCS & 21 & $\begin{array}{c}52 \\
\text { (mean) }\end{array}$ & $61.9 \%$ & Unselected & & & & & & None \\
\hline KaWARAYA [20] & Japan & RCS & 69 & & $34.8 \%$ & $\begin{array}{l}\text { Suspected/known } \\
\text { malignancy }\end{array}$ & & & & $\begin{array}{l}\text { Reported } \\
\text { (malignant) }\end{array}$ & & \\
\hline Katis [11] & Greece & PCS & 37 & $44-78$ & $62.1 \%$ & Unselected & & $\begin{array}{l}\text { Reported } \\
\text { (absent) }\end{array}$ & & & Performed & None \\
\hline IYODA [14] & Japan & RCS & 296 & $\begin{array}{c}62.2 \\
\text { (mean) }\end{array}$ & $83.4 \%$ & $\begin{array}{l}\text { Suspected/known } \\
\text { malignancy }\end{array}$ & & $\begin{array}{l}\text { Reported } \\
\text { (present) }\end{array}$ & & $\begin{array}{l}\text { Reported } \\
\text { (malignant) }\end{array}$ & Performed & \\
\hline LEIRO-FERNÁNDEZ [6] & Spain & PCS & 36 & $\begin{array}{c}65.6 \\
\text { (mean) }\end{array}$ & $30.6 \%$ & Unselected & & $\begin{array}{l}\text { Reported } \\
\text { (present) }\end{array}$ & & & & \\
\hline PIROZYNSKI [21] & Poland & RCS & 24 & & $58.3 \%$ & $\begin{array}{l}\text { Suspected/known } \\
\text { malignancy }\end{array}$ & & & & $\begin{array}{l}\text { Reported } \\
\text { (malignant) }\end{array}$ & & \\
\hline REICHENBERGER [13] & Switzerland & RCS & 152 & $\begin{array}{c}63 \\
\text { (mean) }\end{array}$ & $35.5 \%$ & Unselected & & & & $\begin{array}{l}\text { Reported } \\
\text { (malignant/ } \\
\text { benign) }\end{array}$ & & \\
\hline Rотн [23] & Norway & RCS & 21 & & $19.0 \%$ & $\begin{array}{l}\text { Suspected/known } \\
\text { malignancy }\end{array}$ & & $\begin{array}{l}\text { Reported } \\
\text { (absent) }\end{array}$ & & $\begin{array}{l}\text { Reported } \\
\text { (malignant) }\end{array}$ & & \\
\hline SCHENK [9] & USA & PCS & 42 & & $40.0 \%$ & $\begin{array}{l}\text { Suspected/known } \\
\text { malignancy }\end{array}$ & & & & $\begin{array}{l}\text { Reported } \\
\text { (malignant) }\end{array}$ & & None \\
\hline SHURE [7] & USA & PCS & 42 & $46-77$ & $52.4 \%$ & $\begin{array}{l}\text { Suspected/known } \\
\text { malignancy }\end{array}$ & & $\begin{array}{l}\text { Reported } \\
\text { (absent) }\end{array}$ & & $\begin{array}{l}\text { Reported } \\
\text { (malignant) }\end{array}$ & Performed & None \\
\hline TRISOLINI [5] & Italy & PCS & 218 & $\begin{array}{c}66.7 \\
\text { (mean) }\end{array}$ & $65.0 \%$ & Unselected & Reported & & Reported & $\begin{array}{l}\text { Reported } \\
\text { (malignant/ } \\
\text { benign) }\end{array}$ & Performed & $\begin{array}{l}4 \text { PNT } \\
4 \text { major } \\
\text { bleeding }\end{array}$ \\
\hline WANG $[8]$ & USA & PCS & 20 & & $55.0 \%$ & Unselected & & $\begin{array}{l}\text { Reported } \\
\text { (absent) }\end{array}$ & & & & 1 PNT \\
\hline WANG [18] & USA & PCS & 22 & & $36.3 \%$ & Unselected & & $\begin{array}{l}\text { Reported } \\
\text { (absent) }\end{array}$ & & & Performed & None \\
\hline
\end{tabular}

ROSE: rapid on-site evaluation; CT: computed tomography; TBNA: transbronchial needle aspiration; TBB: transbronchial biopsy; RCS: Retrospective Cohort Study; PCS: Prospective Cohort Study; PNT: pneumothorax. 


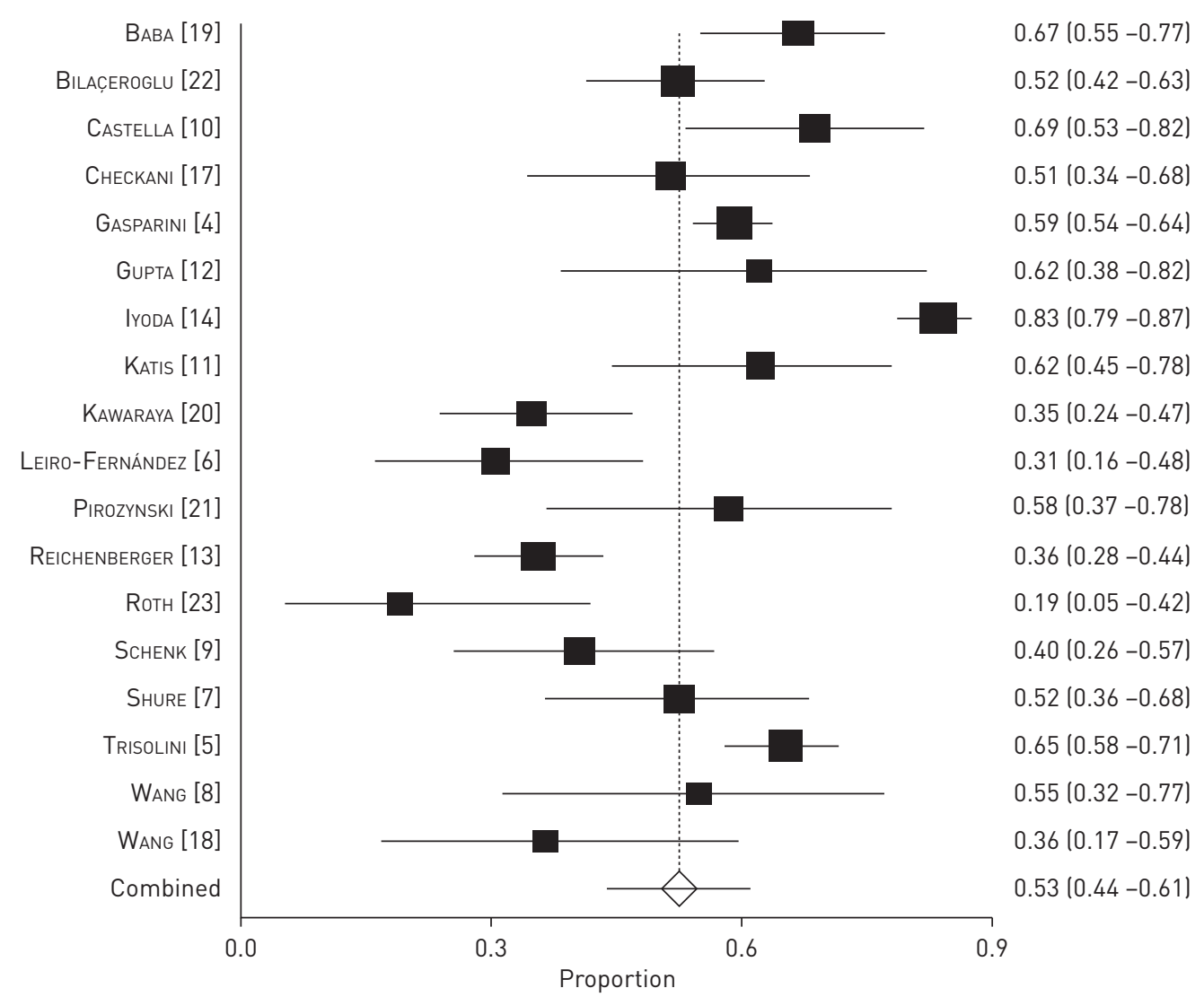

FIGURE 2 Diagnostic yield of transbronchial needle aspiration in the included studies. $1^{2} 90.9 \% 195 \% \mathrm{Cl} 87.7-$ 93.0\%). Error bars represent $95 \%$ confidence intervals.

according to nodule size was reported by two $(11.1 \%)$ out of $18[5,10]$ and according to the presence/ absence of CT bronchus sign by two $(11.1 \%)$ out of $18[5,22]$. The presence/absence of rapid on-site evaluation (ROSE) was reported in $12(66.7 \%)$ out of 18 studies $[4,6-8,10,11,14,17-19,22,23]$. Malignant and benign diseases were diagnosed through TBNA in 10 (55.6\%) out of 18 [4, 5, 7, 9, 13, 14, $19,20,21,23]$ and three $(16.7 \%)$ out of $18[4,5,13]$, respectively. TBNA-related complications were reported by five $(22.2 \%)$ out of $18[4,5,8,17,22]$ articles: seven patients with pneumothorax $[4,5,8,22]$, eight cases of moderate bleeding $[5,17,22]$ and four cases of major bleeding [5] were described in the entire cohort. The comparison of the diagnostic yield between TBNA and transbronchial biopsy (TBB) was performed in seven (38.9\%) out of 18 studies [4, 5, 7, 11, 14, 18, 22] (table 1).

The pooled TBNA yield, computed on 18 individual studies [4-14, 17-23], was 0.53 (95\% CI 0.4-0.6) ( $\mathrm{I}^{2}$ 90.9\%, 95\% CI 87.7-93.0\%) (figure 2). According to the CT bronchus sign [5, 22], the pooled TBNA yield was 0.70 (95\% CI 0.6-0.8) ( $\mathrm{I}^{2}$ not available) when the bronchus sign was present and 0.51 (95\% CI 0.4-0.6) $\left(\mathrm{I}^{2}\right.$ not available) when it was absent (figure 3). A pooled TBNA yield of 0.51 (95\% CI 0.4-0.6) ( $\mathrm{I}^{2} 63.0 \%$,

a) BiLAC̣ERoglu [22]

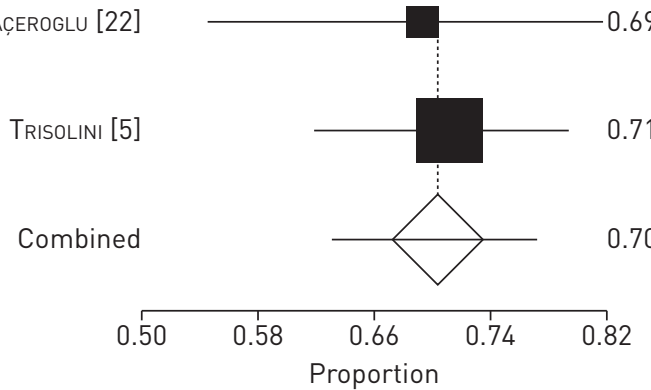

b) BiLAC̣EROgLu [22]
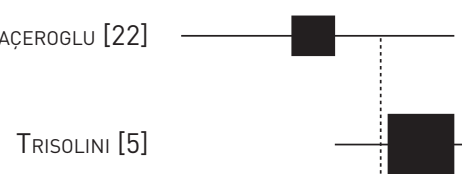

$71(0.62-0.79)$

$.70(0.63-0.77)$
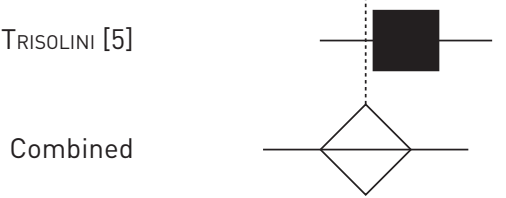

0.2
$0.42(0.25-0.61)$

$0.56(0.45-0.67)$

$0.51(0.38-0.64)$

FIGURE 3 Diagnostic yield of transbronchial needle aspiration according to the computed tomography (CT) bronchus sign. a) CT bronchus sign positive. b) CT bronchus sign negative. Error bars represent $95 \%$ confidence intervals. 
a) $B$

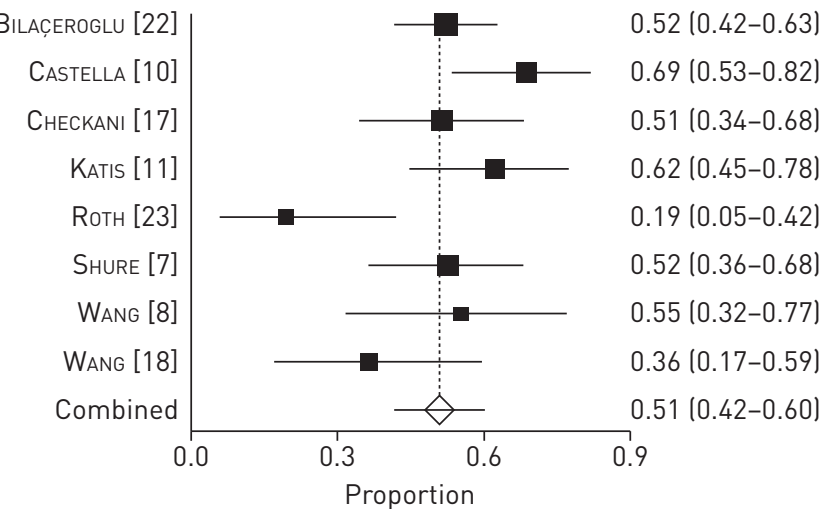

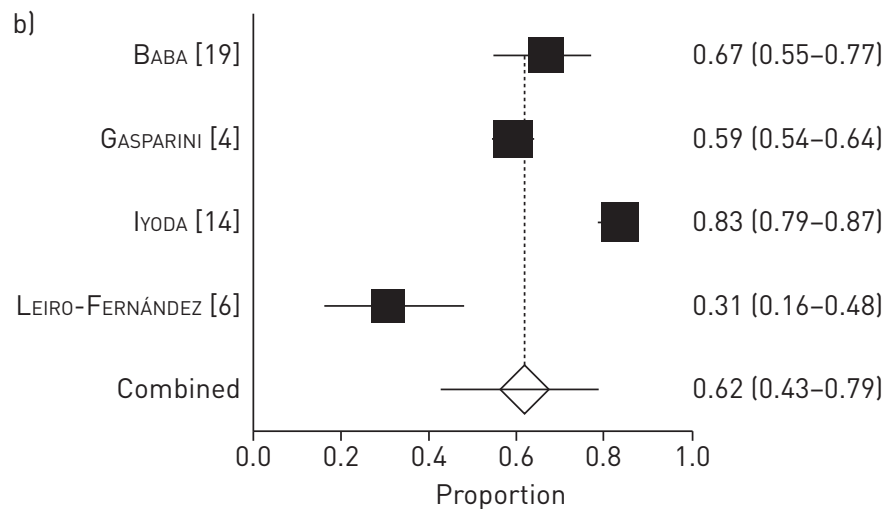

FIGURE 4 Diagnostic yield of TBNA according to the rapid on-site evaluation (ROSE) presence. a) ROSE absent. $I^{2} 63 \%$ (95\% CI 0-81\%). b) ROSE present. $\mathrm{I}^{2} 96 \%$ (95\% Cl 93.2-97.3\%). Error bars represent $95 \%$ confidence intervals.

95\% CI 0.0-81.0\%) was found when ROSE was not carried out $[7,8,10,11,17,18,22,23]$ and $0.62(95 \%$ CI 0.4-0.8) (I $\mathrm{I}^{2} 96 \%$, 95\% CI 93.2-97.3\%) when it was performed $[4,6,14,19]$ (figure 4). In the case of malignant lesions $[4,5,7,9,13,14,19,20,23]$, pooled TBNA yield was higher $(0.55$, 95\% CI 0.4-0.7) ( $\mathrm{I}^{2} 93.2 \%, 95 \%$ CI 90.2-95.0\%) if compared with cases of benign lesions [4, 5, 13] $(0.17,95 \%$ CI $0.1-0.2)$ ( $\mathrm{I}^{2} 0.0 \%$, 95\% CI $0.0-72.9 \%$ ) (figure 5). When the authors evaluated lesions $>3 \mathrm{~cm}[5,10]$, the TBNA diagnostic yield was 0.81 (95\% CI 0.7-0.9) ( $\mathrm{I}^{2}$ not available); the pooled proportion was 0.55 (95\% CI 0.5-0.6) ( $\mathrm{I}^{2}$ not available) in cases of lesions $\leqslant 3 \mathrm{~cm}[5,10]$ (figure 6). TBNA showed a higher diagnostic yield $(0.60)$ ( $\mathrm{I}^{2}$ 92.2\%, 95\% CI 86.9-94.7\%) than TBB (0.45) (I² 85\%, 95\% CI 68.5-91\%) [4, 5, 7, 11, 14, 18, 22] (figure 7).

The application of the QUADAS-2 tool revealed an overall low methodological quality. It presents the judgement of risk of bias, concerns about applicability for each domain, and the final summarised proportion of studies deemed as at "low" or "high" risk of bias and having "low" or "high" concerns regarding applicability of the review question (online supplementary figure S1). Overall, five studies were judged to be at low risk of bias $[4,5,7,11,17]$, seven as having low concerns about applicability $[4,5,7$, $8,10,11,17]$ and, out of these, two studies met both the conditions $[5,7]$.

\section{Discussion}

The present systematic review and meta-analysis firstly provides an extensive description and synthesis of the main results from all published studies evaluating fluoroscopy-guided TBNA yield and predictors for the diagnosis of PPL. Overall, the pooled estimate documented an acceptable diagnostic performance (0.53, 95\% CI 0.4-0.6). Major predictors of a higher sensitivity included the presence of CT bronchus sign, the malignant nature of the abnormalities, diameter of the lesions $>3 \mathrm{~cm}$ and ROSE employment. Data on comparison between TBNA and TBB, resulting only from studies in which both procedures were performed in the same patients, showed a significant superiority of TBNA. Considering that, based on the
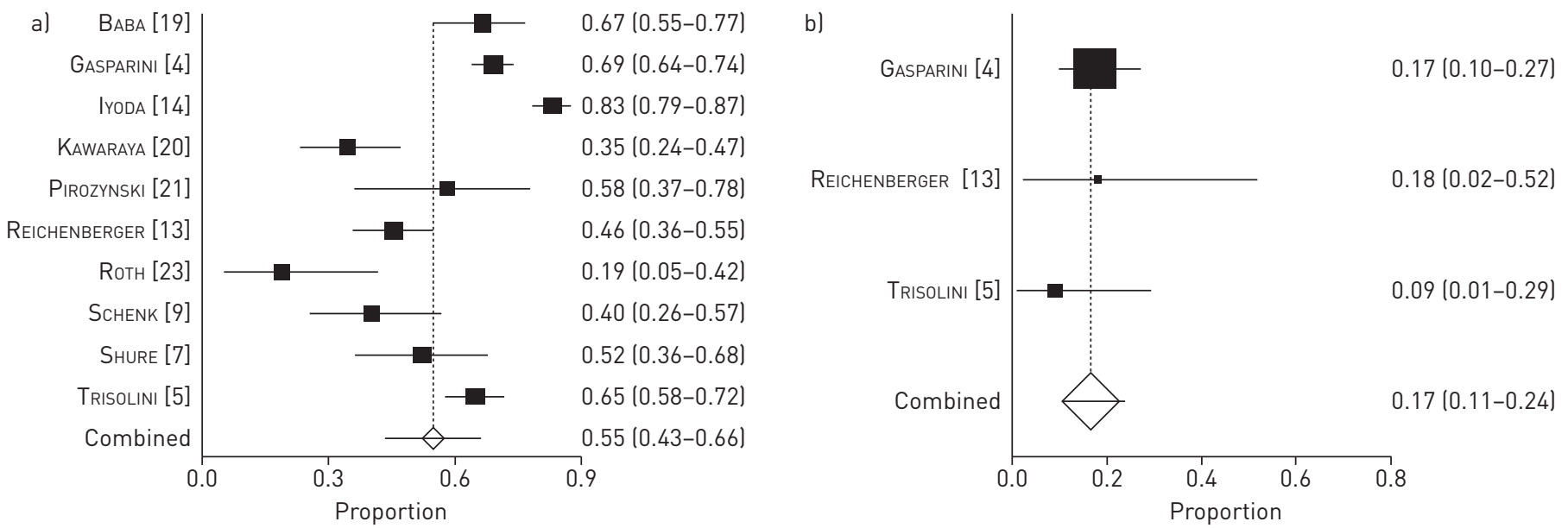

FIGURE 5 Diagnostic yield of transbronchial needle aspiration according to the malignancy of the lesions. a) Malignant lesions. $I^{2} 93.2 \%(95 \% \mathrm{Cl}$ $90.2-95 \%$ ). b) Benign lesions. $1^{2} 0 \%$ (95\% Cl 0-72.9\%). Error bars represent $95 \%$ confidence intervals. 
a)

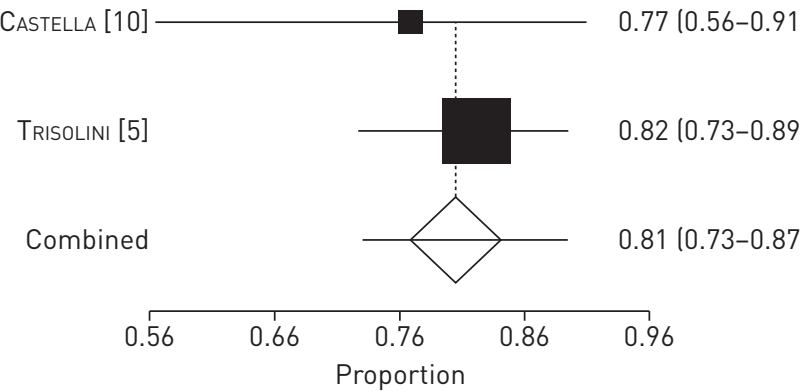

b)

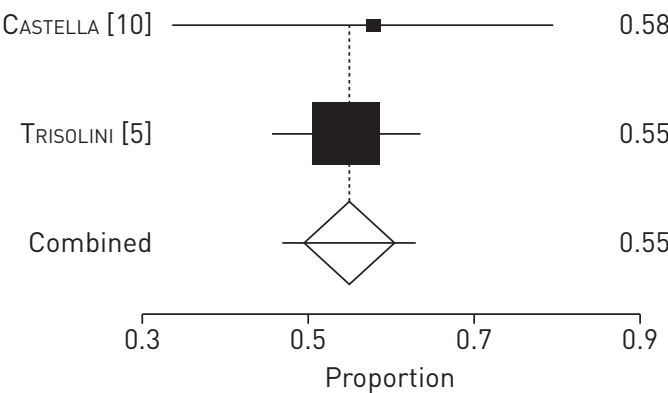

$0.58(0.33-0.80)$

$0.55(0.46-0.64)$

$0.55(0.47-0.63)$

FIGURE 6 Diagnostic yield of transbronchial needle aspiration according to lesion size. a) $>3 \mathrm{~cm}$. b) $\leqslant 3 \mathrm{~cm}$. Error bars represent $95 \%$ confidence intervals.

literature, TBNA is still largely underused while TBB is the most employed technique in this context, this result is of great relevance $[1,5,6]$.

Randomised controlled trials have previously suggested the importance of ROSE of needle aspirates in both central malignant lesions, and hilar and mediastinal adenopathies. In the former, the immediate cytological assessment may improve the sensitivity of this sampling technique; in the latter, it may reduce the number of biopsy sites and the complication rate of bronchoscopy without enhancing the yield of TBNA [24, 25]. In sampling peripheral lesions, the only data available came from uncontrolled studies [26, 27]. However, our subgroup analysis suggested ROSE as a potential predictor of a better yield. Furthermore, the ROSE technique may allow bronchoscopists to stop sampling when sufficient material has been harvested for traditional diagnosis and molecular studies, thus potentially avoiding useless TBBs or brushings [28, 29].

Further subanalyses support the previous findings that malignant lesions $[4,5,13]$ and the presence of a CT bronchus sign $[5,22]$ are associated with a better yield. Actually, it should be noted that even in the absence of CT bronchus sign, TBNA offers a good diagnostic performance (pooled yield of 51\%). As suggested by some authors, this aspect might be explained by the peculiar ability of this sampling method to pierce the bronchial wall, reaching lesions with a peribronchial growth $[5,7,8]$.

TBNA showed a higher yield in sampling peripheral masses than in diagnosing nodules. Moreover, it is worth noting that the diagnostic performance of TBNA in lesions with a diameter $\leqslant 3 \mathrm{~cm}$ is not negligible (pooled yield of 53\%). These results encourage performing conventional TBNA during the first bronchoscopic examination in every PPL that is visible by fluoroscopy; in about half of cases, this might spare the patients from undergoing diagnostic procedures with a higher risk of complications, such as transthoracic needle aspiration [5]. Our analysis suggests that TBNA is also a safe procedure with a limited number of adverse events, pneumothorax and bleeding being the most frequent complications.

Although less powerful and technologically advanced in comparison with electromagnetic navigation and EBUS guidance, fluoroscopy-guided bronchoscopic procedures should be learnt after specific training to improve technical skills. Furthermore, adequate infrastructures and equipment, as well as the possible inclusion of other healthcare workers (e.g. radiology technicians and pathologists), may be deemed as potential limitations in terms of costs, time and radiation exposure.

Some limitations of the present review have to be acknowledged. In particular, there was a high baseline heterogeneity among studies in terms of design, sample size and outcome measures. Moreover, several
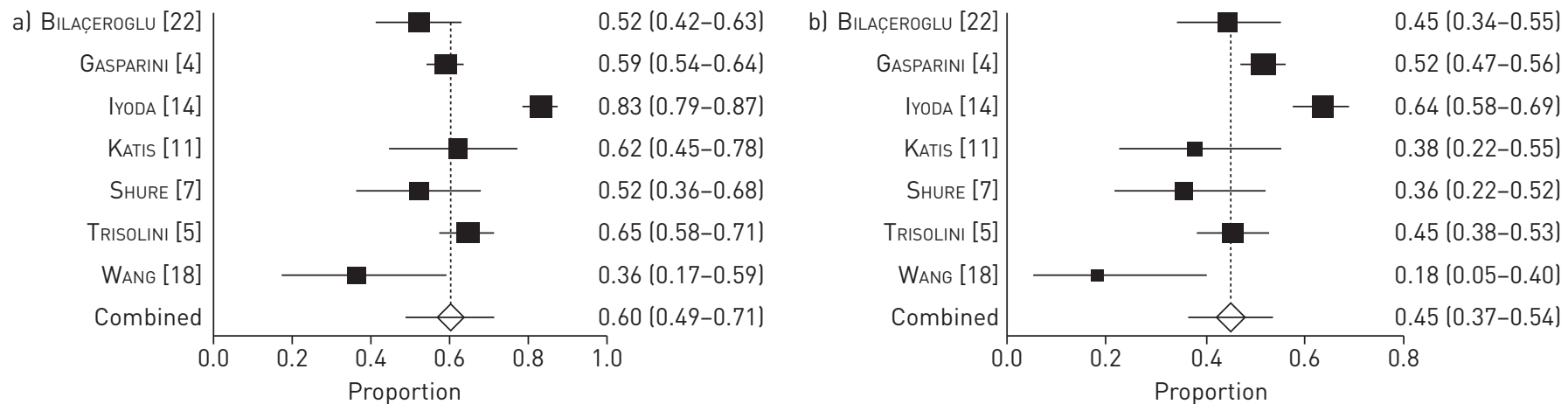

FIGURE 7 Diagnostic yield of transbronchial needle aspiration (TBNA) compared with transbronchial biopsy (TBB). a) TBNA yield. ${ }^{2} 92.2 \%$ (95\% Cl 86.9-94.7\%). b) TBB yield. $\left.\right|^{2} 85.0 \%$ (95\% Cl 68.5-91\%). Error bars represent $95 \%$ confidence intervals. 
confounding factors could have affected the performance and interpretation of index test, as TBNA was often performed by different operators and with different numbers of passes within the same study. Indeed, the majority of the studies did not include important information on operators' skills (experienced endoscopists/fellows, and number and experience of pathologists), sampling method and equipment (bronchoscope and needle type, needle pass number, and presence/absence of ROSE) and targeted lesions (method of nodule/mass measurement). A further limitation includes the definition of "diagnostic samples" among studies. In the era of targeted lung cancer therapy, a sample should be considered as diagnostic only if provides an amount of cells suitable for both immunocytochemical and molecular studies, but in most of investigations, it was unclear whether this was routinely obtained. Finally, considering that a nondiagnostic or negative result does not rule out the possibility of malignancy, the lack of a standardised reference test, as documented by our QUADAS-2 results, is also highly likely to influence the interpretation of results. However, the evidence provided could help scientists for the design of novel studies on this topic, addressing the aforementioned limitations.

\section{Conclusions}

Our systematic review and meta-analysis suggests that fluoroscopy-guided TBNA is a useful and safe diagnostic technique for the diagnosis of PPLs, but its accuracy seems to be related to selected clinical and procedural aspects, such as presence of CT bronchus sign, an underlying malignant process, diameter of the lesions $>3 \mathrm{~cm}$ and ROSE employment.

Despite the above mentioned limitations, our results are particularly remarkable in this era of new advances in endoscopic procedures. Although these innovative technologies have recently broadened the bronchoscopist's horizons, their diffusion is still limited, particularly in developing countries, and the routinely diagnostic approach to PPLs is still represented by fluoroscopy-guided transbronchial and percutaneous sampling. In this context, it is reasonable to propose a sequential diagnostic algorithm, as previously suggested [4], in which flexible bronchoscopy with TBNA should be performed first, due to the acceptable sensitivity and the safer profile, especially in presence of predictors of positive aspirates.

\section{References}

1 Rivera MP, Mehta AC, Wahidi MM. Establishing the diagnosis of lung cancer diagnosis and management of lung cancer, 3rd ed. American College of Chest Physicians evidence-based clinical practice guidelines. Chest 2013; 143: e142S-e165S.

2 Steinfort DP, Khor YH, Manser RL, et al. Radial probe endobronchial ultrasound for the diagnosis of peripheral lung cancer: systematic review and meta-analysis. Eur Respir J 2011; 37: 902-910.

3 Welker JA, Alattar M, Gautam S. Repeat needle biopsies combined with clinical observation are safe and accurate in the management of a solitary pulmonary nodule. Cancer 2015; 103: 599-607.

4 Gasparini S, Ferretti M, Bichi Secchi E, et al. Integration of transbronchial and percutaneous approach in the diagnosis of peripheral pulmonary nodules or masses. Experience with 1027 consecutive cases. Chest 1995; 108: 131-137.

5 Trisolini R, Cancellieri A, Tinelli C, et al. Performance characteristics and predictors of yield from transbronchial needle aspiration in the diagnosis of peripheral pulmonary lesions. Respirology 2011; 16: 1144-1149.

6 Leiro-Fernández V, Botana Rial M, Represas Represas C, et al. Cost-effectiveness analysis of transbronchial needle aspiration of pulmonary lesions without endobronchial affectation. Arch Bronconeumol 2012; 48: 448-452.

7 Shure D, Fedullo PF. Transbronchial needle aspiration of peripheral masses. Am Rev Respir Dis 1983; 128: 1090-1092.

8 Wang KP, Haponik EF, Britt EJ, et al. Transbronchial needle aspiration of peripheral pulmonary nodules. Chest 1984; 86: 819-823.

9 Schenk DA, Bryan CL, Bower JH, et al. Transbronchial needle aspiration in the diagnosis of bronchogenic carcinoma. Chest 1987; 92: 83-85.

10 Castella J, Buj J, Puzo C, et al. Diagnosis and staging of bronchogenic carcinoma by transtracheal and transbronchial needle aspiration. Ann Oncol 1995; 6: S21-S24.

11 Katis K, Inglesos E, Zachariadis E, et al. The role of transbronchial needle aspiration in the diagnosis of peripheral lung masses or nodules. Eur Respir J 1995; 8: 963-966.

12 Gupta D, Gulati M, Rajwanshi A. Fluoroscopic transbronchial fine needle aspiration for diagnosis of peripheral pulmonary nodules. Indian J Chest Dis Allied Sci 1996; 38: 163-167.

13 Reichenberger F, Weber J, Tamm M, et al. The value of transbronchial needle aspiration in the diagnosis of peripheral pulmonary lesions. Chest 1999; 116: 704-708.

14 Iyoda A, Baba M, Shibuya K, et al. Transbronchial fine needle aspiration cytological examination: a useful tool for diagnosing primary lung cancer. Thorac Cardiovasc Surg 2006; 54: 117-119.

15 Moher D, Liberati A, Tetzlaff J, et al. Preferred Reporting Items for Systematic Reviews and Meta-Analyses: the PRISMA statement. PLoS Med 2009; 6: e1000097.

16 Whiting PF, Rutjes AW, Westwood ME, et al. QUADAS-2: a revised tool for the quality assessment of diagnostic accuracy studies. Ann Intern Med 2011; 155: 529-536.

17 Checkani V. Bronchoscopic diagnosis of solitary pulmonary nodules and lung masses in the absence of endobronchial abnormality. Chest 1996; 109: 620-625.

18 Wang KP, Britt EJ. Needle brush in the diagnosis of lung mass or nodule through flexible bronchoscopy. Chest 1991; 100: 1148-1150. 
19 Baba M, Iyoda A, Yasufuku K, et al. Preoperative cytodiagnosis of very small-sized peripheral-type primary lung cancer. Lung Cancer 2002; 37: 277-280.

20 Kawaraya M, Gemba K, Ueoka H, et al. Evaluation of various cytologic examinations by bronchoscopy in the diagnosis of peripheral lung cancer. Br J Cancer 2003; 89: 1885-1888.

21 Pirozynski M. Bronchoalveolar lavage in the diagnosis of peripheral, primary lung cancer. Chest 1992; 102: 372-374.

22 Bilaçeroglu S, Kumcuoglu Z, Alper H, et al. CT bronchus sign guided bronchoscopic multiple diagnostic procedures in carcinomatous solitary multiple nodules and masses. Respiration 1998; 65: 49-55.

23 Roth K, Hardie JA, Andreassen AH, et al. Predictors of diagnostic yield in bronchoscopy: a retrospective cohort study comparing different combinations of sampling techniques. BMC Pulm Med 2008; 8: 2.

24 Mondoni M, Carlucci P, Di Marco F, et al. Rapid on-site evaluation improves needle aspiration sensitivity in the diagnosis of central lung cancers: a randomized trial. Respiration 2013; 86: 52-58.

25 Trisolini R, Cancellieri A, Tinelli C, et al. Rapid on-site evaluation of transbronchial aspirates in the diagnosis of hilar and mediastinal adenopathy: a randomized trial. Chest 2011; 139: 395-401.

26 Davenport RD. Rapid on-site evaluation of transbronchial aspirates. Chest 1990; 98: 59-61.

27 Diette GB, White P Jr, Terry P, et al. Utility of on-site cytopathology assessment for bronchoscopic evaluation of lung masses and adenopathy. Chest 2000; 117: 1186-1190.

28 Van der Heijden EH, Casal RF, Trisolini R, et al. Guideline for the acquisition and preparation of conventional and endobronchial ultrasound-guided transbronchial needle aspiration specimens for the diagnosis and molecular testing of patients with known or suspected lung cancer. Respiration 2014; 88: 500-517.

29 Gasparini S. It is time for this "ROSE" to flower. Respiration 2005; 72: 129-131. 